\title{
Smart Chicken Poultry Farm Using IoT Techniques
}

\author{
Faisal Syafar, Misita Anwar, Ridwansyah
}

\begin{abstract}
This research aims to design a monitoring system for temperature, humidity, and harmful gas levels in chicken coops using an internet of things (IoT) based system. The system design uses a DHT 22 sensor to detect temperature and humidity and an MQ-135 sensor to monitor the quality of ammonia gas (NH3). The designed system is also expected to control the fan and lights to maintain the cage's stable temperature and humidity. The data from the two sensors are connected to the internet network with the ESP8266 module and the Arduino Mega 2560 microcontroller. The data is then displayed on the LCD and sent to the smartphone application for remote notification via an 800L GSM SIM. Based on the test data carried out later, it can be concluded whether this IOT-based control system provides convenience for farmers to reduce mortality and delays in chicken growth. If successful, the data can be accessed in real-time using a smartphone application.
\end{abstract}

\section{Index Terms-Smart system, Chicken farm, IoT}

\section{INTRODUCTION}

Food availability is a basic need for humans. Cases of poisoning or disease due to consuming contaminated food have occurred in Indonesia, so its availability needs special attention in terms of quality and quantity.

The prospect of laying hens in Indonesia is considered very good in domestic and foreign markets when viewed from the supply and demand side. On the supply side, the production capacity of laying hens in Indonesia has not yet reached the actual production capacity. The production capacity can be seen from the number of breeding, animal feed, and pharmaceutical companies still producing below-installed capacity. The development prospects are still open. On the demand side, currently, the production of broiler chicken eggs only meets the needs of the domestic market by $65 \%$ [1]. The rest is filled with free-range chicken, duck, and quail eggs. The global trade climate, which has begun to be felt at this time, has increasingly made it possible for broiler egg products from Indonesia to go to foreign markets, considering that broiler products are elastic to changes in the annual per capita income of a country. Although the potential for laying hens is very attractive, some challenges can be a barrier to business that can turn potential profits into losses.

The current problem in laying hens in Indonesia is using manual methods such as human labor to harvest eggs and provide feed. Meanwhile, what we know now is that

Faisal Syafar, Department of Electronics, Universitas Negeri Makassar, Makassar, Indonesia

Misita Anwar, Department of Electronics, Universitas Negeri Makassar, Makassar, Indonesia

Ridwansyah, Department of Electronics, Universitas Negeri Makassar, Makassar, Indonesia
Indonesia wants to enter the industrial world 4.0. In the industrial world 4.0, companies will take advantage of IoT, cloud technology, and big data. In other words, human workers will be replaced by robots.

The problem is how to design and build a prototype by implementing IoT for monitoring and controlling broiler chicken coops using multiple sensors? This study aims to design an IoT device for laying hens using several IoT sensors. The hope is that this IoT device can help lay hens in carrying out their activities. Internet of Things (IoT) technology is also proposed in chicken farm management to improve chicken health and meat quality [2]. Furthermore, this paper consists of a theoretical foundation, research methods followed by results and discussion, future research, and closes with a conclusion.

\section{THEORETICAL FOUNDATION}

To know the condition and quality of an environment, one no longer needs to wait for information announcements or come to the relevant government agencies. The use of IoT in environmental monitoring can be applied to the livestock sector. IoT can help someone in knowing the quality of the environmental conditions that will be used for livestock. In this case, it is how to find out which farms are suitable for building a chicken farm.

\section{A. Internet of Things-Based Monitoring System Design}

Maintaining the temperature in chickens' homes is generally done by regularly visiting the coop, but as technology develops, many implement the Internet of Things (IoT) system. IoT is a concept where particular objects can transmit data over a network without any human interaction. One application of IoT is in a toxic gas monitoring system in chicken coops [3], [4].

Air quality and the environment significantly affect the health of chickens. The most dominant substance polluting the air in the chicken coop is ammonia produced by chicken manure. Other environmental variables that affect the health of chickens are temperature and humidity. The problem faced by smallholder chicken farmers is the declining health of chickens, leading to death caused by poor air and environmental quality [5]. This environmental variable is often estimated by farmers manually using the five senses. This manual estimate is very likely to produce invalid results.

Designing an intelligent monitoring and control system for laying hens based on the internet of things positively impacts technological developments in the livestock sector [6]. This process starts from several system designs, namely use case diagrams, system relationship diagrams, block diagrams, mechanical design implementation systems, electronic design implementations, software implementations, and system testing and system performance evaluation. 


\section{Smart Chicken Poultry Farm Using IoT Techniques}

\section{B. Internet of Things}

The Internet of Things (IoT) is a structure in which objects and people are provided with an exclusive identity and the ability to move data over a network without requiring two-way human-to-human, i.e., source-to-destination or human-to-computer interaction. IoT is a technological development that promises to optimize life with intelligent sensors and networked objects and work together on the internet. Various everyday appliances with intelligent sensors have been created and controlled via the internet. Analog data is converted into digital data through intelligent sensors and then sent to the processor in real-time [7]. Thus, it is possible to automate remotely controlled equipment in the IoT architecture [8].

\section{How the Internet of Things Works}

The way IoT works is that every object must have an Internet Protocol (IP) address. An Internet Protocol (IP) address is an identity on a network ordered from other objects on the same network. Next, these objects' Internet Protocol (IP) addresses will be connected to the internet network. Nowadays, an internet connection is straightforward. Thus users can monitor objects and even give commands (remote control) to these objects with an internet connection [9].

Sensors on objects allow the object to obtain the information it needs. After obtaining the information, the object can process the information itself and even communicate with other objects with IP addresses and are connected to the internet. There is an exchange of information in communication between these objects. After complete information processing, the object can work by itself or even order other objects to work.

\section{Chicken House}

The temperature of the chicken's house that is suitable for raising chickens ranges from 32.2 to $35{ }^{\circ} \mathrm{C}$, humidity (60-70\%), lighting, and heating of the cage according to existing rules [10]. The layout of the cage so that it gets morning sunlight and does not fight strong wind direction and good air circulation, do not build a cage with a hilly land surface because it blocks air circulation and endangers surface water flow when it rains, it is better if the cage is built with an open system so that the wind blows enough to provide freshness in the cage. The construction of the cage does not have to be with expensive materials, and the important thing is that it is robust, clean, and durable. The main advantage of implementing IoT for monitoring variables in nature is that it allows variables to be observed remotely, continuously, and in real-time [11].

\section{RESEARCH METHOD}

The design of this system is done to build a system that can observe and control conditions in chicken farms. This system is designed using several sensors connected to the internet connection to send conditions to the farm and control it when conditions do not match the ideal conditions. Furthermore, data from these sensors is sent to the API $t$ and displayed on a smartphone.

\section{A. System Architecture}

This electronic system takes a case study on an open system cage widely used by chicken farms. The cage manager can use the monitoring system developed to monitor whether the temperature in the cage is appropriate, too hot, or too cold. In addition, the system can be used to monitor ammonia gas levels in the cage. After getting this data, the cage manager will take appropriate action so that the condition of the chicken coop can be maintained in a comfortable condition for the chickens. The developed system adopts Internet of Things (IoT) technology.

The system architecture consists of a temperature sensor (DHT 22), and an ammonia gas sensor (MQ-135) used to detect and convert the temperature and content of ammonia gas into an electronic signal which is then processed by the microcontroller system (Arduino Mega 2560). The amount of temperature and ammonia gas content is then displayed on the Liquid Crystal Display (LCD) viewer and sent to the microcontroller to be sent to the cell phone of the cage manager.

\section{B. Hardware Design}

The system architecture is realized in an electronic circuit in the form of an MQ-135 sensor that will produce an output in the form of an analog signal which is then sent to the Arduino Mega microcontroller port for further processing. The DHT-22 sensor has a digital data output which is then sent to the Arduino Mega microcontroller port. The temperature data and ammonia gas processed by the Arduino Mega microcontroller are then sent to a smartphone.

\section{Software Design}

Software or a program developed for the Arduino Mega microcontroller is needed. The computational stage begins with preparation, namely the initialization of the sensors used, namely MQ-135 and DHT-22. Then the calibration process is carried out on the sensor, namely between the sensor output and the range of values received by the Arduino Mega microcontroller. After getting the sensor reading data, the Arduino Mega microcontroller computes the amount of temperature and ammonia gas read by the sensor and then displays it on the LCD viewer and sends it to a smartphone. The research scheme can be seen in Figure 1 below.

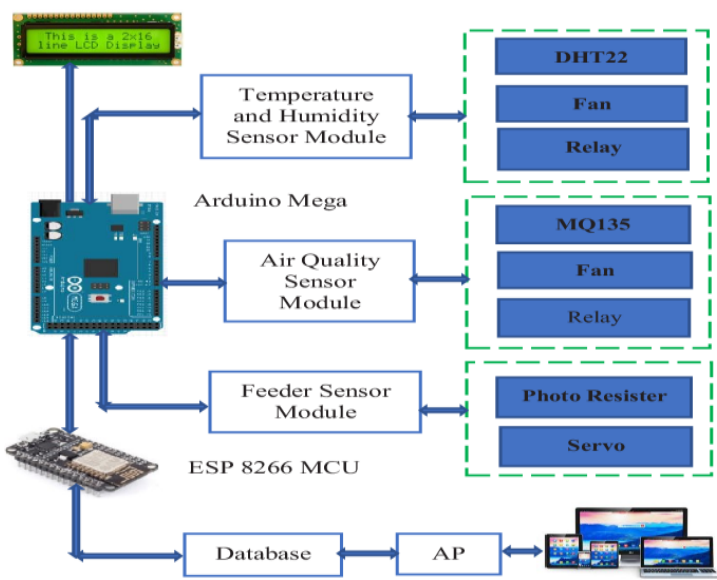

Figure 1. Schematic of research design 


\section{FINDINGS AND DISCUSSION}

The results of the system design that have been produced can be seen in Figure 2 below. Based on the above diagram, some mechanical components have been committed, including Exhaust Fan, Heating Fan, and Cooling Fan.

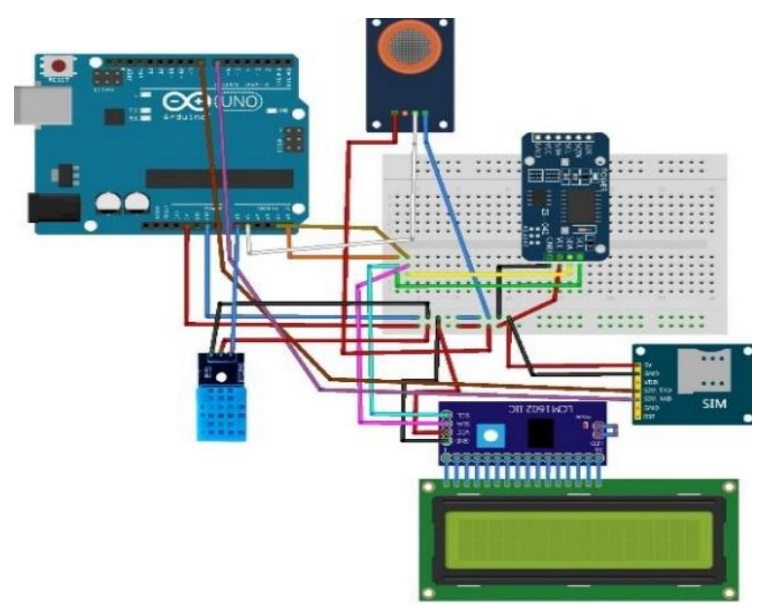

Figure 2. Design of a chicken coop monitoring system

The DHT22 sensor is used to record air temperature and humidity. MQ-135 sensor for recording ammonia levels. Connectivity using SIM800L GSM module. Setting the time for sending data recordings using RTC. The hardware that processes the above components is the Arduino UNO Mega. After conducting a literature study and observations on several similar systems, it was concluded that the DHT-22 sensor is quite effective for use in this research design because the sensor can produce two data at once, namely temperature and humidity.

The temperature and humidity data were recorded using the DHT-22 sensor. The DHT-22 sensor is a digital signal calibration sensor capable of providing temperature and humidity information. This sensor is classified as a component with a perfect level of stability and very accurate calibration features. The calibration coefficient is stored in one-time-programmable (OTP) program memory, so that when the internal sensor detects something, this module includes the coefficient in its calculations with signal transmission up to 20 meters, with specifications Supply Voltage: $+5 \mathrm{~V}$, Temperature range: 0 - $50{ }^{\circ} \mathrm{C}$ error of \pm two ${ }^{\circ} \mathrm{C}$, Humidity: $20-90 \% \mathrm{RH} \pm 5 \% \mathrm{RH}$ error.

The cage air quality data was recorded using the MQ-135 sensor. The MQ-135 gas sensor is a chemical sensor sensitive to NH3, NOx, alcohol, benzene, smoke (CO), $\mathrm{CO} 2$ compounds.

Recorded data from both sensors will be sent to the smartphone after the data is processed in the GSM SIM800L module. The SIM800L is a quad-band GSM/GPRS module, operating at $850 / 900 / 1800 / 1900 \mathrm{MHz}$ frequencies. The SIM800L features class 12/class 10 multi-slot GPRS (optional) and supports GPRS encoding scheme. With a tiny configuration of $15.8 * 17.8 * 2.4 \mathrm{~mm}$, SIM800L can meet almost all space requirements in user applications, such as smartphones, PDAs, and other mobile devices.

\section{FUTURE RESEARCH}

The following stages of research (system development) will be carried out within the next two years. The continuation of the research design above is the system development stage. At the development stage, all sensors will be tested before being assembled. The test is compared with conventional temperature and humidity measuring devices commonly used by chicken breeders.

Testing from the connectivity side also determines that the smartphone manager of the cage has successfully received the recorded data via short message. This test scenario is carried out to prove whether the system is running as expected.

The monitoring system that will be developed is also equipped with a notification system such as the example shown in Figure 3; namely, the system will provide notifications via a smartphone if the ammonia gas level exceeds a certain level, the amount of which can be changed according to the required criteria.

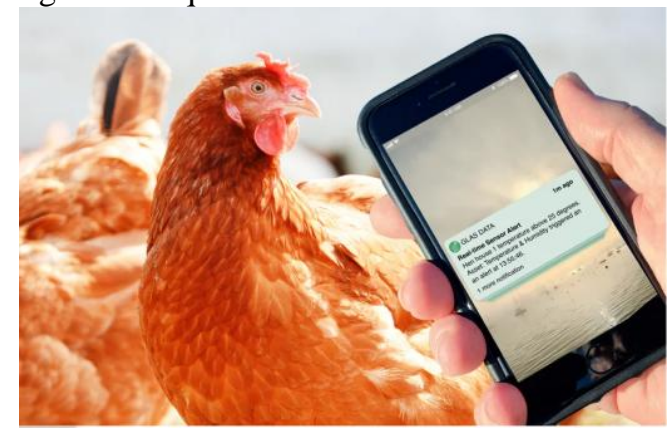

Figure 3. Alert notification on the smartphone

\section{CONCLUSION}

The monitoring of broiler chicken house systems using IoT technology is expected to monitor and control how the state of the livestock is owned. With this arrangement, the livestock kept will be healthier and more fertile so that the profits will be even greater. The benefit that can be felt is that monitoring the environmental conditions of broiler chicken coops, especially temperature, humidity, and ammonia, can be done more quickly and easily even though the location of the cages is spread out in different locations. The selection of sensors is expected to be quite effective because, with the DHT-22 and MQ-135, the system can generate three types of data. The GSM SIM800L module can also answer the problem of choosing connectivity considering the inequality of internet network infrastructure in each location of the cage.

\section{ACKNOWLEDGMENT}

This work is supported and funded by the Directorate Research and Community Engagement (DRPM), Ministry of Education, Culture, Research and Technology of Indonesia. Funding support is more appreciated, Funding Number: 282/E4.1/AK.04.PT/2021 dan 149/UN36.9/LP2M/2021.

\section{REFERENCES}

[1] Direktorat Jendral Peternakan dan Kesehatan Hewan (Ditjenpkh) "Statistik Peternakan dan Kesehatan Hewan" Jakarta. Direktorat Jendral Peternakan dan Kesehatan Hewan Kementerian Pertanian RI. 2018.

[2] I. E. Gonzales, M. G. Omella, S. Ferreiro, I. Fernandez, I. Lazaro, and E. Garcia, "An IoT platform towards the enhancement of poultry production chains," Sensors, vol. 20, 2020, pp. 1-20. 
[3] P.S. Maliselo, and G.K. Nkonde, "Ammonia production in poultry houses and its effect on the growth of Gallus Gallus Domestica (broiler chickens): a case study of a small scale poultry house in riverside, Kitwe, Zambia," International Journal of Scientific \& Technology Research, vol. 4(4), 2015, pp. 141-145.

[4] I. Kilic, and E. Yaslioglu, "Ammonia and carbon dioxide concentrations in a layer house," Asian Australasian Journal of Animal Science, vol. 27(8), 2018, pp. 1211-1218.

[5] A. A. G. Raj, and J. G. Jayanthi, "IoT-based real-time poultry monitoring and health status identification," in 11th International Symposium on Mechatronics and its Applications, ISMA 2018.

[6] G. Corkery, S. Ward, C. Kenny, and P. Hemmingway, "Incorporating Smart Sensing Technologies into the Poultry Industry,"Journal of World's Poultry Research, vol. 3(4), 2013, pp. 106-128.

[7] L. S. Handigolkar, M. L. Kavya, and P. D. Veena, "IoT Based Smart Poultry Farming using Commodity Hardware and Software," Bonfring Int. J. Softw. Eng. Soft Comput., vol. 6, 2017, pp. 171-175.

[8] R. B. Mahale, and S. S. Sonavane, "Smart poultry farm monitoring using IoT and wireless sensor networks," Int. J. Adv. Res. Comput. Sci., vol. 7(3), 2016, pp. 187-190.

[9] M. Ammad-Uddin, M. Ayaz, E. H. Aggoune, and M. Sajjad, "Wireless sensor network: A complete solution for poultry farming," ISTT 2014 2014 IEEE 2nd Int. Symp. Telecommun. Technol., 2015, pp. 321-325.

[10] F. Haiwei, J. Youhua, D. Jijun, and Z. Jingle, "Low-Temperature Cross-Sensitivity Humidity Sensor Based on a U-Shaped Microfiber Interferometer," IEEE Sensors Journal, Vol. 17(3), 2016. pp. 644-649.

[11] M. Logan, M.Safi, P. Lens, and C. Visvanathan, "Investigating the performance of internet of things based anaerobic digestion of food waste," Process Safety and Environmental Protection, vol. 127, 2019, pp. 277-287. 